\title{
EXCERTOS
}

\section{Angela Dimitrakaki}

\section{Como des/articular um sistema: repetição e diferença no trabalho de Maria Lucia Cattani}

\section{Resumo}

O artigo comenta o trabalho de Maria Lucia Cattani a partir de conceitos como repetição, diferença e identificação, em que os signos elaborados nos trabalhos reconfiguram repetição e diferença como dois territórios possivelmente sobrepostos no espaço da arte, em um processo de trabalho desdobrado no tempo.

\section{Palavras-chave}

Maria Lucia Cattani. Repetição. Diferença. Grade. 
Nota do Editor. Artigo originalmente publicado no website de Maria Lucia Cattani, em tradução não creditada. Resumo e palavras-chave foram acrescentados pelos editores.
O discurso da arte nas últimas duas décadas tem sido conectado com questões de diferença. Apresentada com a prerrogativa do pós- modernismo, a diferença veio para significar o oposto ao unificado e estabilizado objeto do modernismo. A dicotomia entre o objeto moderno e sua consequente dissolução é uma das fantasias do pós-modernismo como um milieu cultural.

0 trabalho de Maria Lucia Cattani remete-se aos limites desta fantasia por investigar os limites da repetição, por intersectar a ilusão da absoluta identificação e por construir diferença como uma série de sutis variações registradas sobre uma grade. Os trabalhos são construídos como uma recusa simbólica a reduzir o complexo jogo de similaridade e diferença em dois conceitos claramente definidos e opostos. Pelo contrário, os signos elaborados nos trabalhos reconfiguram repetição e diferença como dois territórios possivelmente sobrepostos no espaço da arte. Os pictogramas emergentes são ordenados pela artista para enfatizar a constante negociação desses dois elementos.

Contudo essa negociação não é uma afirmação forçada do trabalho. A artista apresenta meios visuais para a negociação tomar lugar, mas os parâmetros finais são da parte da consciência do espectador. Cattani tem conseguido provar que uma forte presença visual não deve ser sempre identificada com a agressividade da imagem. Os trabalhos são sugeridos mais do que autoevidentes e em sua aproximação com uma linguagem eles requerem um tipo diferente de engajamento daqueles demandados por trabalhos tipicamente pós-modernos, os quais deliberadamente perdem seus espectadores em uma desordenada justaposição de signos. A linguagem visual desenvolvida por Cattani leva em consideração algo dessa desordem e transcreve-a em uma possibilidade e incerteza de um código que pode ser nunca quebrado.

A interação (ou mesmo incerta distinção?) entre repetição e diferença, entre unidade e ruptura, finitude e infinitas variações sugere não somente as múltiplas possibilidades frequentemente negadas pela fixação dos paradigmas culturais, mas também por uma certa inadequação de linguagem quando lidando com limites dos processos como os que os trabalhos desta exposição emergem. Nesse sentido, apesar do fato que o trabalho evoca as vicissitudes da 
escrita como a sedimentação das energias da psique, eles permanecem autoconscientemente visuais. A desconstrução estética do par diferença e repetição mobilizado por Cattani parece confirmar o enunciado de Michael Baxandall que "a linguagem não é suficientemente equipada para oferecer um comentário sobre um determinado quadro [...] o repertório de conceitos que oferece para descrever uma superfície plana sustentando uma porção de formas sutilmente variadas e ordenadas é bruto e remoto". 5

O processo do trabalho, desdobrado no tempo, é parte integrante do balanço que o trabalho procura estabelecer ou desafiar. Demanda concentração, persistência e dia a dia adquire a qualidade de um ritual. A artista seleciona cuidadosamente seus materiais. Ela cava suas marcas num pequeno e maleável bloco de matéria flexível como a borracha, ao invés do que nos mais tradicionais e menos flexíveis blocos de madeira. As marcas são impressas sobre a transparência de delicados papéis chineses. Seguindo a rotação dos blocos a imagem muda. Algumas vezes as marcas de um bloco diferente são impostas sobre as marcas do primeiro bloco. A cor lentamente empalidece até que torna-se a sombra do que foi uma vez. Então nova tinta é adicionada e o jogo começa novamente. Contudo, o que é esse jogo? É o jogo de rabiscar. Rabiscar é o primeiro processo de fazer cultura. Cattani cria ambientes visuais de signos com a sutil ironia característica de um agente pós-moderno. Ela cria contextos. Ela estabelece regras cujo poder é ocasionalmente negado para finalmente definir a taxonomia das imagens. 0 trabalho emergente é simultaneamente previsível e imprevisível. 0 momento de liberdade, o momento de gravar suas marcas no material não tão duro, não tão macio é seguido por uma denúncia deliberada daquela liberdade em um relativamente limitado conjunto de decisões que constituem o procedimento do qual o trabalho emerge. Significativamente, este momento original de liberdade uma vez foi concebido como o momento quando a autoria era estabelecida. Uma vez, em uma era diferente da nossa. Uma vez, como no modernismo. Porque nesses trabalhos a artista subverteu as marcas de sua autoria de maneira formidável. É impossível decidir se esses trabalhos constituem um processo de escrita ou um processo de gradual silenciar, apagar. As regras do jogo estão lá e contudo constantemente quebradas: cores esmaecendo e depois revigoradas, marca intensas e meros traços fornecem as ambiguidades da cadeia semântica confrontando o espectador. A qualquer momento o espectador é confrontado por ambos, o eu do sujeito criativo e o não sujeito do acaso.

É incerto se junto com o trabalho um senso de identidade também emerge. De acordo com a psicanálise Lacaniana, é a repetição que estabelece a identidade. Mas o tipo de repetição apresentada ao espectador nesses trabalhos não é nunca atingido como tal por causa da interface das variações. No momento
1. Michael Baxandall, Patterns of Intention: On the Historical Explanation of Pictures, New Haven and London, Yale University Press, 1985, p. 3. 
2. Mieke Bal and Norman Bryson, "Semiotics and Art History", The Art Bulletin, June 1991, p. 199. que essas divergências são levadas em conta a concretização da identidade é negada ao espectador tão quanto ao artista. Desse ponto em diante a história fica pessoal e interpretação é o que conta. Alguns espectadores escolherão ignorar as variações e focarão no trabalho como uma confiante e acertada totalidade, uma questão de simetria. Outros não serão capazes de apreender o trabalho como um sistema fechado, pois eles serão capazes de ver as fendas no sistema, as assimetrias quase imperceptíveis que impedem do trabalho ser concluído. A reprodução desse dilema, tão esquematicamente expresso aqui, é o que situa culturalmente o trabalho e o que garante sua historicidade. 0 trabaIho é construído como um comentário sobre a produção da estética no pós-modernismo. Ele emprega uma dialética de polissemia e revela a divisão entre ordem perfeita e presumível natureza caótica do signo num mundo profundamente problemático repleto de imagens midiáticas.

Ainda há outra reviravolta na história. A localização do pós-moderno é contra-atacada pela forma do signo o qual, já mencionado, lembra um tipo de escrita, um tipo de ansiedade transcrevida que previamente definiu uma linguagem não totalmente inteligível, uma palavra que elevou-se ao status de fetiche, sustentando uma inidentificável ausência. A repetição serial da imagem não consegue preencher essa lacuna. Mas compensa ao construir, por meio da repetição novamente, sua própria narratividade. Esse modelo de narratividade carrega escassa semelhança aos modelos tradicionais, tais quais aqueles frequentemente associados com o entendimento convencional do realismo. As marcas no(s) bloco(s) rodado(s) sugerem que o que é percebido como a "realidade" do trabalho é produzido pela ilusão (a não realidade) da repetição. A fisicalidade da marca nunca é oferecida não mediada ao espectador. É mediada pela resposta do espectador à operação simultânea de uma ilusão. As marcas são reais, mas há várias maneiras igualmente válidas de aproximação à sua "realidade" e isso traz-nos de volta a Lacan, que arguiu que "sujeito humano não tem direto acesso à realidade". ${ }^{6} 0$ modo com que a realidade é inscrita no trabaIho de Cattani é de grande importância para o entendimento da diferença entre esse tipo de trabalho e outros trabalhos pós-modernos. Com base nas tradições da arte pop, a superfície do trabalho pós-moderno parece perpetuamente estupefata pela velocidade e persistência da imagem que viaja o mundo, como se não existisse tempo suficiente para o artista pós-moderno elaborar padrões de desafirmação. Mas as imagens nesta exibição não parecem em nada submergidas. Ao contrário, elas parecem exploratórias. Cattani procede através das descontinuidades da repetição e diferença, através das sutilezas de seu ambivalente engajamento com a imagem que nunca é declaradamente emocional, nem declaradamente cerebral: incorporando o pequeno dentro do grande, estendendo ou cortando as margens, oferecendo a iconografia de um sistema e 
ao mesmo tempo transgredindo as normas desse sistema. Na interface de todos esses elementos apresenta-se a autorreflexão de sua arte.

Angela Dimitrakaki, 1998

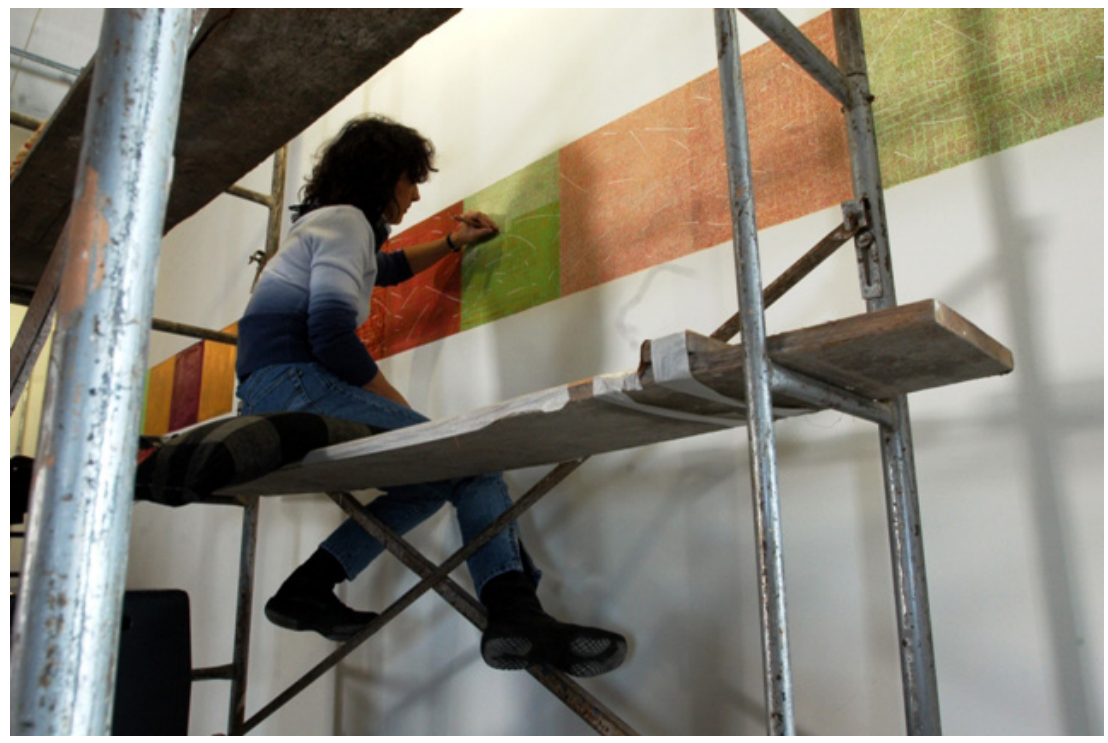

Fonte: Adriana Franciosi, Clic RBS/ jornal Zero Hora, Porto Alegre, 2010

\section{Angela Dimitrakaki}

Doutora, pesquisadora e professora de História e Teoria da Arte Contemporânea na University of Edinburgh. Autora de Gender, ArtWork and the Global Imperative: A Materialist Feminist Critique (Manchester University Press) e Art and Globalisation: From the Postmodern Sign to the Biopolitical Arena (Hestia Athens, em grego), ambos em 2013. É também escritora ficcional, publicando em seu grego nativo. 
